\title{
A NOTE ON AN EXTENSION OF LINDELÖF'S THEOREM TO MEROMORPHIC FUNCTIONS
}

\author{
MOHAMMAD SALMASSI \\ Department of Mathematics \\ University of Rhode Island \\ Kingston, Rhode Island 02881 U.S.A. \\ (Received April 27,1983)
}

ABSTRACT. S. M. Shah [3] has given an extension of Lindelöf's Theorem to meromorphic functions. He also obtained an expression for the characteristic function of a meromorphic function of integer order. In this note we give estimates for $\log \left|f\left(\mathrm{re}^{i \theta}\right)\right|$ of such functions.

KEY WORDS AND PHRASES. meromorphic functions, proximate order, slowly changing functions.

AMS (MOS) SUBJECT CLASSIFICATION (1980) CODES. 30D30

\section{INTRODUCTION.}

In [3;theorem 1] S. M. Shah obtained an expression for the characteristic functinn $T(r, f)$ of a meromorphic function $f(z)$ of integer order $p$. Following the argument of Cartwright $[2$; theorem 45,46$]$ we can obtain the following results for $\left.\log \mid f(r e)^{1 \theta}\right) \mid$. We write

$$
n(r)=n(r, 1 / f)+n(r, f) ; N(r)=N(r, 1 / f)+N(r, f) .
$$

Since $\rho$ is a positive integer, we can write $f(z)$ in the form (see [3])

$$
f(z)=z^{k} \exp \left(c z^{\rho}+\ldots\right) \prod_{1}^{\infty} E\left(z / a_{n}, \rho\right) \prod_{1}^{\infty} E\left(z / b_{n}, \rho\right) \text {. }
$$

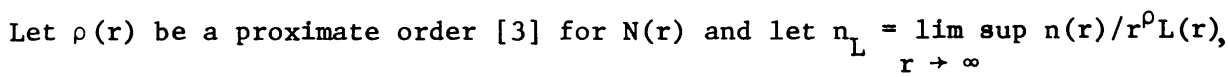
where $L(r)$ is a slowly changing function.

2. MAIN RESULTS.

THEOREM. Let $f(z)$ be a meromorphic function of integer order $\rho>0$ and let

$$
S(r)=c+\frac{1}{\rho}\left|a_{n}\right| \leq r^{a_{n}^{-\rho}-\frac{1}{\rho}} \mid b_{n} \sum \leq r^{b_{n}^{-\rho}},
$$


i. Suppose $n_{L}<\infty$. Then for every $n>0$, there is a $K(\rho, \eta)$ such that for every $\varepsilon>0$,

$$
|\log | f\left(r e^{i \theta}\right)\left|-\operatorname{Re}\left(r^{\rho} e^{i \Theta} s(r)\right)\right|<K(\rho, n)\left(n_{L}+\varepsilon\right) r^{\rho} L(r)
$$

for $0 \leq r \leq R$, except perhaps in circles the sum of whose radii is less than $n R$, provided that $R_{>} R_{0}(\varepsilon, \eta)$.

ii. Suppose $N(r)$ is of order $\rho$. Then there is a $K(\rho, \eta)$ such that

$$
|\log | f\left(r e^{i \theta}\right)\left|-\operatorname{Re}\left(r^{\rho} e^{i \theta} S(r)\right)\right|<K(\rho, \eta) r^{\rho(r)}
$$

for $0 \leq r \leq R$, except perhpas in circles the sum of whose radil is less than $\eta R$, provided that $R>R_{0}(n)$.

iii. Let $\lim _{r \rightarrow \infty} \sup \log N(r) / \log r=c_{1}<\rho$ and $\operatorname{let} c_{1}<c_{2}<\rho \leq 1+c_{2}$. Then for every $n>0$, there is a $K\left(c_{2}, n\right)$ such that

$$
\left|\log f\left(r e^{i \theta}\right)\right|-\operatorname{Re}\left(r^{\rho} e^{i \Theta} s(r)\right) \mid<K\left(c_{2}, n\right) r^{c} 2
$$

for $0 \leq r \leq R$, except perhaps in circles the sum of whose radii is less than $n R$, provided that $R>\mathrm{K}_{\mathrm{O}}\left(\mathrm{c}_{2}, n\right)$. The proof depends on the following lemma of Cartan (see [1;p.46], also $[2 ; \mathrm{pp} .73-77])$ :

LEMA (H. Cartan). Let $p(z)=\prod_{k=1}^{n}\left(z-z_{k}\right)$; for any positive $H$, the inequality

$$
|\mathrm{p}(\mathrm{z})|>(\mathrm{H} / \mathrm{e})^{\mathrm{n}}
$$

holds outside at most $\mathrm{n}$ circles the sum of whose radii is at most $2 \mathrm{H}$.

We omit the details of the proof of the theorem.

\section{REFERENCES}

1. Boas, R. P. Entire Functions, Academic Press, New York, 1954.

2. Cartwright, M. L. Integral Functions, Cambridge Univ. Press, Cambridge, 1956.

3. Shah, S. M. An Extension of Lindelof's Theorem to Meromorphic Functions, Tohoku Math. J. 12(1960),pp. 333-338. 


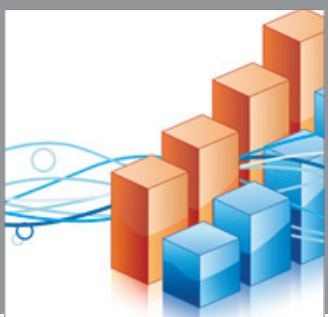

Advances in

Operations Research

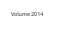

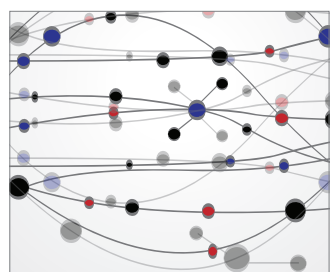

\section{The Scientific} World Journal
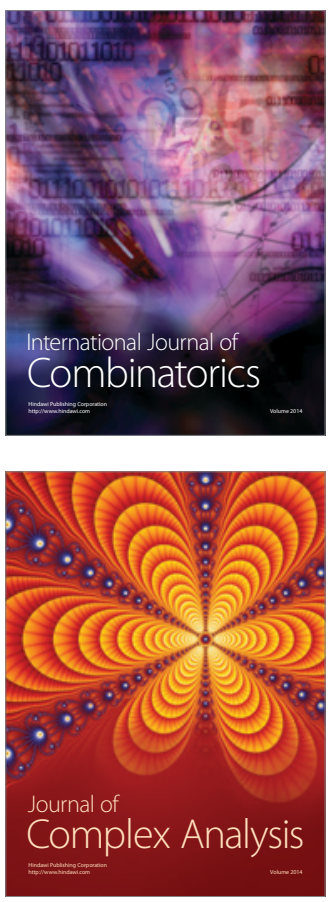

International Journal of

Mathematics and

Mathematical

Sciences
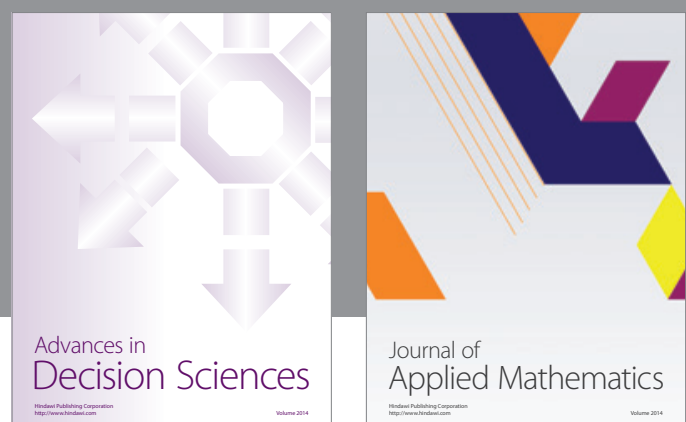

Journal of

Applied Mathematics
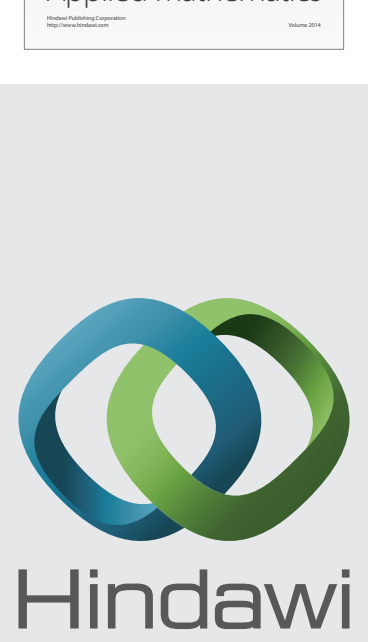

Submit your manuscripts at http://www.hindawi.com
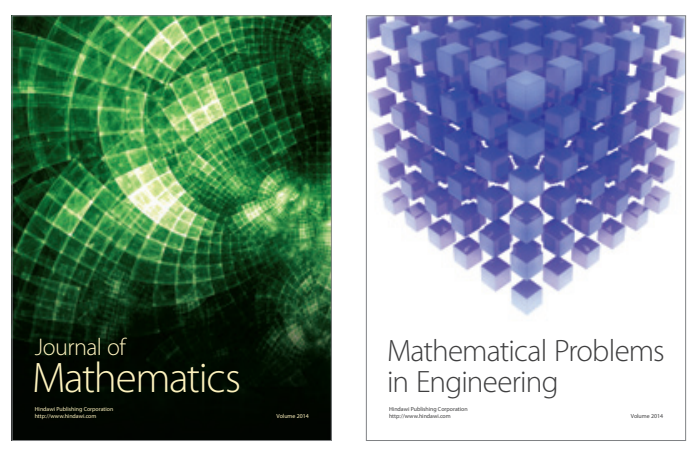

Mathematical Problems in Engineering
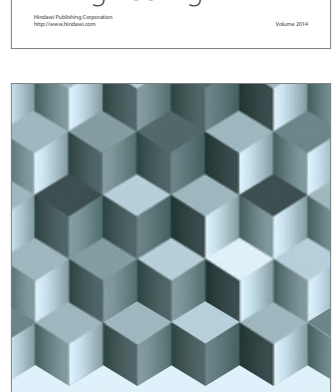

Journal of

Function Spaces
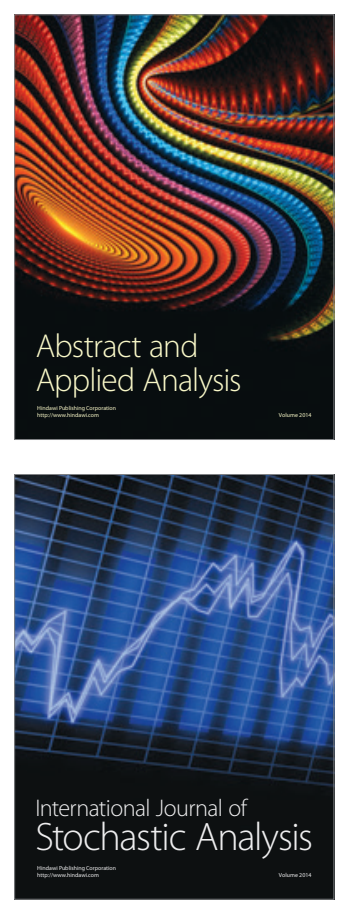

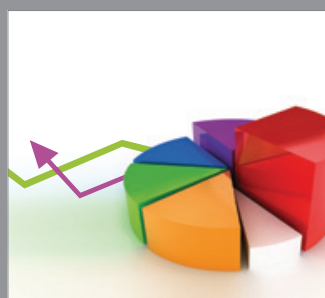

ournal of

Probability and Statistics

Promensencen
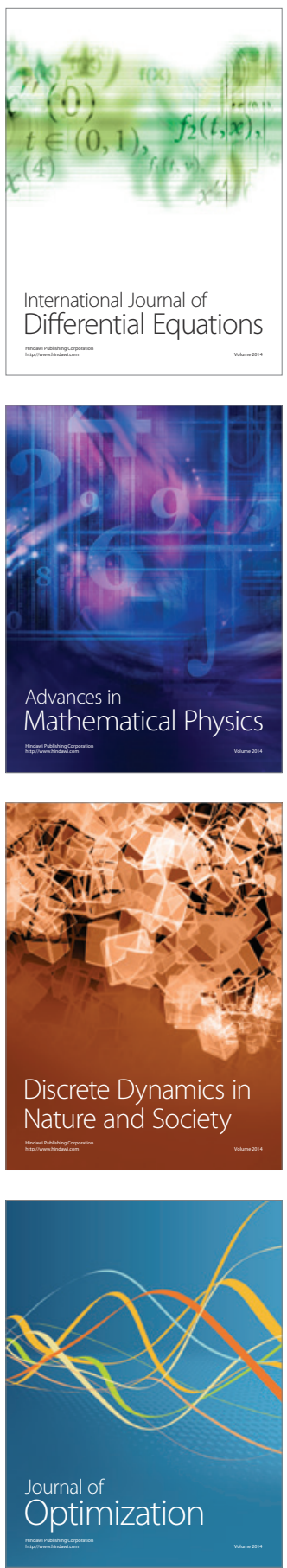